\title{
Validation of the 8th Edition of the American Joint Committee on Cancer Staging System for Gallbladder Cancer and Implications for the Follow-up of Patients without Node Dissection
}

\author{
You-Na Sung, $M D^{1}$ \\ Minjeong Song, MD2 \\ Jae Hoon Lee, MD, $\mathrm{PhD}^{3}$ \\ Ki Byung Song, MD, PhD 3 \\ Dae Wook Hwang, MD, $\mathrm{PhD}^{3}$ \\ Chul-Soo Ahn, MD, PhD ${ }^{3}$ \\ Shin Hwang, MD, PhD 3 \\ Seung-Mo Hong, MD, $P h D^{1}$
}

\begin{abstract}
${ }^{1}$ Department of Pathology, Asan Medical Center, University of Ulsan College of Medicine, Seoul, ${ }^{2}$ Department of Pathology, Kyung Hee University Hospital at Gangdong, Seoul, ${ }^{3}$ Department of Surgery, Asan Medical Center, University of Ulsan College of Medicine, Seoul, Korea
\end{abstract}

Correspondence: Seung-Mo Hong, MD, PhD Department of Pathology, Asan Medical Center, University of Ulsan College of Medicine, 88 Olympic-ro 43-gil, Songpa-gu, Seoul 05505, Korea Tel: 82-2-3010-4558

Fax: 82-2-472-7898

E-mail: smhong28@gmail.com

Received May 19, 2019

Accepted September 29, 2019

Published Online October 17, 2019

*This work was presented, in part, at the 69th annual fall meeting of the Korean Society of Pathologists, Seoul, Republic of Korea; October 31 to November 2, 2017.

\begin{abstract}
Purpose
The 8th edition of gallbladder cancer staging in the American Joint Committee on Cancer (AJCC) staging system changed the $\mathrm{T}$ and $\mathrm{N}$ categories.
\end{abstract}

\section{Materials and Methods}

In order to validate the new staging system, a total of 348 surgically resected gallbladder cancers were grouped based on the 8th edition of the T and $\mathrm{N}$ categories and compared with patients' survival.

\section{Results}

Significant differences were noted between T1b-T2a $(p=0.003)$ and T2b-T3 $(p<0.001)$ tumors, but not between Tis-T1a, T1a-T1b, and T2a-T2b tumors. However, significant survival differences were observed both by the overall and pair-wise (T1-T2, T2-T3) comparisons (all, $p<0.001$ ) without dividing T1/T2 subcategories. When cases with $\geq 6$ examined lymph nodes were evaluated, significant survival differences were observed among the entire comparison $(p<0.001)$ and pair-wise comparisons of NO-N1 $(p=0.001)$ and N1-N2 ( $p=0.039)$ lesions. When cases without nodal dissection (NX) were additionally compared, significant survival differences were observed between patients with NO-NX ( $p=0.001)$ and NX-N1 $(p<0.001)$ lesions.

\section{Conclusion}

The T category in the 8th edition of the AJCC staging system did not completely stratify the prognosis of patients with gallbladder cancer. Modification by eliminating T subcategories can better stratify the prognosis. In contrast, the N category clearly determines patients' survival with $\geq 6$ examined lymph nodes. The survival time in patients of gallbladder cancers without nodal dissection is between NO and N1 cases. Therefore, close postoperative followed up is recommended for those patients.

\section{Introduction}

Gallbladder cancer is the most common malignancy of the biliary tract with a wide range of geographical variability and prevalence. Its prevalence is reportedly higher in Chile, Poland, India, Pakistan, Ecuador, Japan, and Korea [1], but lower in the Western countries, including the United States, United Kingdom, Australia, and New Zealand [2]. Gallbladder cancers are detected either incidentally or by symptom
Key words

Gallbladder, Cancer, Stage, Survival, Prognosis 
staging are important to determine the appropriate treatment.

The new 8th edition of the American Joint Committee on Cancer (AJCC) staging of gallbladder cancer changed tumor (T) and lymph nodal (N) categories and stage groups (Table 1). The main changes in the T category were as follows: the previous T2 (wherein the tumor invades the perimuscular connective tissue) in the 7th edition was subdivided into T2a (peritoneal side) and T2b (hepatic side) based on tumor location [9]. Tumors were classified as being located on the peritoneal side (T2a) when cancer cell infiltration is close to the free serosal side of the gallbladder or as being located on the hepatic side (T2b) when cancer cell infiltration is close to the hepatic side without direct invasion into the hepatic parenchyma or into the gallbladder wall attached to the liver [10].

The previous $\mathrm{N}$ category in the 7th edition that was defi- ned based on the anatomical location of the lymph nodes was changed to the number of metastatic lymph nodes [11]. Nodal categories were defined as N1 (1-3 metastatic lymph nodes) and N2 ( $\geq 4$ metastatic lymph nodes) in the 8th edition [12]. In addition, the 8 th edition recommended to examine more than six lymph nodes for accurate staging of the nodal category [9].

In the present study, the prognostic validity of the current 8th AJCC cancer staging system of gallbladder cancer was investigated and compared with the 7th edition. Additionally, we evaluated which clinicopathologic parameters were most associated with patients' survival after the surgical resection of gallbladder cancers.

Table 1. Changes in $\mathrm{T}$ and $\mathrm{N}$ categories and stage grouping from the 7th and 8th edition schemes of the American Joint Committee on Cancer's cancer staging manual

\begin{tabular}{|c|c|c|}
\hline \multicolumn{2}{|r|}{ 7th edition scheme } & 8th edition scheme \\
\hline \multicolumn{3}{|c|}{ T category } \\
\hline Tis & Carcinoma in situ & \\
\hline T1a & Limited to the lamina propria & \\
\hline $\mathrm{T} 1 \mathrm{~b}$ & Invades the muscle layer & \\
\hline $\mathrm{T} 2$ & Invades the perimuscular connective tissue & \\
\hline T2a & & $\begin{array}{l}\text { Invades the perimuscular connective tissue } \\
\text { on the peritoneal side }\end{array}$ \\
\hline $\mathrm{T} 2 \mathrm{~b}$ & & $\begin{array}{l}\text { Invades the perimuscular connective tissue } \\
\text { on the hepatic side }\end{array}$ \\
\hline T3 & \multicolumn{2}{|c|}{$\begin{array}{l}\text { Perforates the serosa and/or directly invades the liver and/or other adjacent organs or structures } \\
\text { (stomach, duodenum, colon, pancreas, omentum, or extrahepatic bile ducts) }\end{array}$} \\
\hline T4 & \multicolumn{2}{|c|}{ Invades the main portal vein or hepatic artery or two or more extrahepatic organs or structures } \\
\hline \multicolumn{3}{|c|}{$\mathrm{N}$ category } \\
\hline No & No regional metastasis & \\
\hline $\mathrm{N} 1$ & $\begin{array}{l}\text { Metastasis to the nodes along the cystic duct, } \\
\text { common bile duct, hepatic artery, and/or portal vein }\end{array}$ & Metastasis in 1-3 regional lymph nodes \\
\hline N2 & $\begin{array}{l}\text { Metastasis to the periaortic, pericaval, superior mesentery } \\
\text { artery, and/or celiac artery lymph nodes }\end{array}$ & Metastasis in $\geq 4$ regional lymph nodes \\
\hline \multicolumn{3}{|c|}{ Stage group } \\
\hline 0 & TisN0M0 & TisN0M0 \\
\hline I & T1N0M0 & T1N0M0 \\
\hline II & T2N0M0 & \\
\hline IIA & & T2aNOM0 \\
\hline IIB & & T2bN0M0 \\
\hline IIIA & T3NOM0 & T3N0M0 \\
\hline IIIB & T1N1M0, T2N1M0, T3N1M0 & T1N1M0, T2N1M0, T3N1M0 \\
\hline VIA & T4N0M0, T4N1M0 & T4N0M0, T4N1M0 \\
\hline VIB & Any T, N2M0 & Any T, N2M0 \\
\hline & Any T, Any N, M1 & Any T, Any N, M1 \\
\hline
\end{tabular}



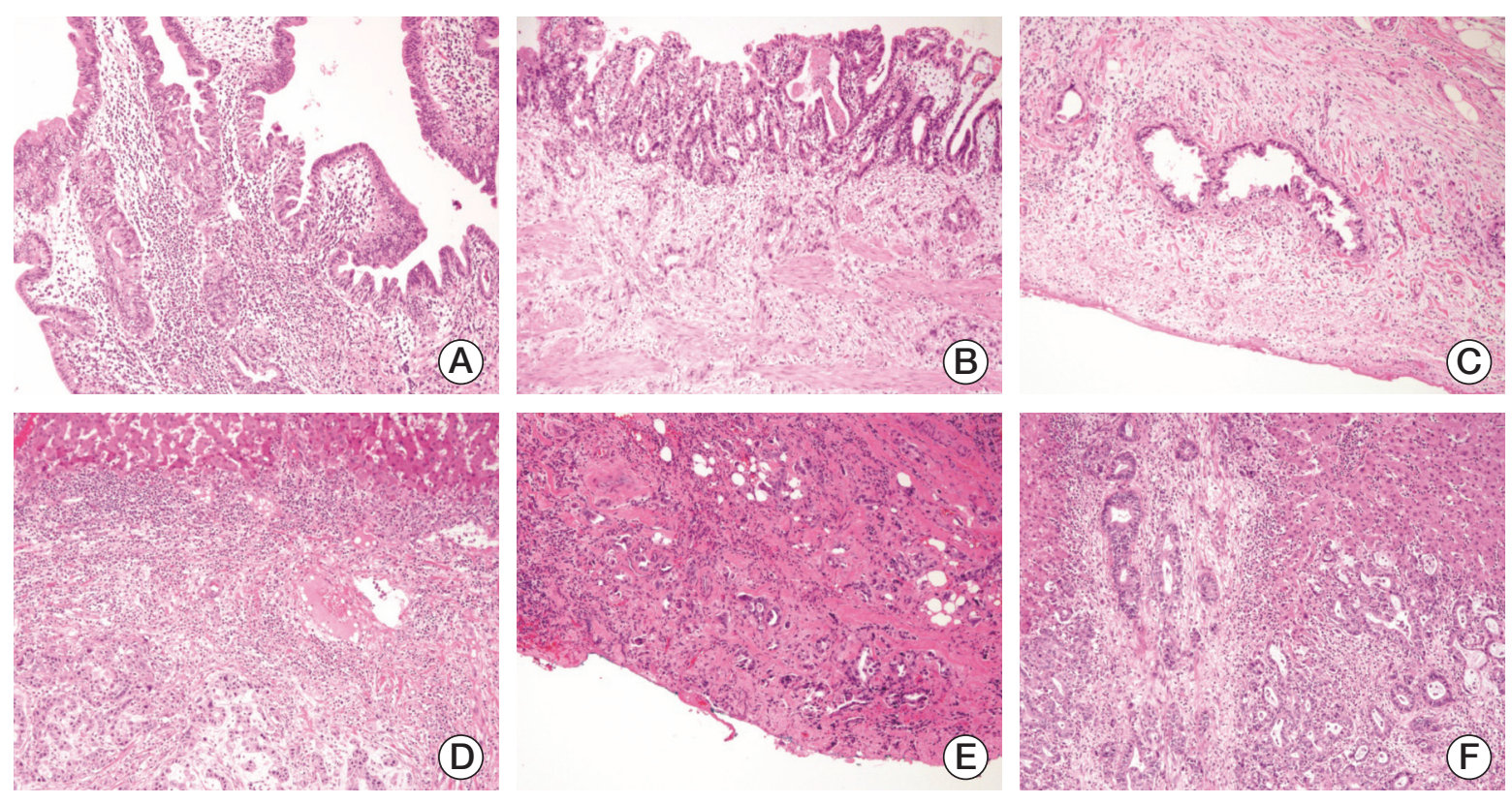

Fig. 1. Representative images of the $\mathrm{T}$ category of the 8 th American Joint Committee on Cancer staging system scheme based on cancer cell infiltration. Cancer cells infiltrate to the lamina propria, T1a $(\times 200)(\mathrm{A})$, muscle layer, T1b $(\times 100)(B)$, peritoneal side of the perimuscular connective tissue, $\mathrm{T} 2 \mathrm{a}(\times 100)(\mathrm{C})$, hepatic side of the perimuscular connective tissue, $\mathrm{T} 2 \mathrm{~b}(\times 100)(\mathrm{D})$, penetrates the serosa, T3 $(\times 100)(\mathrm{E})$, to the liver parenchyma, T3 (magnification, $\times 100)(\mathrm{F})$.

\section{Materials and Methods}

\section{Case selection}

A total of 348 patients who underwent surgical resection of gallbladder cancer from 2005 to 2012 were retrieved from the records of the Department of Pathology at the Asan Medical Center, University of Ulsan College of Medicine. Only carcinomas with their epicenter in the gallbladder were included in this study. Carcinomas arising from extra- or intra-hepatic bile ducts with extension to the gallbladder were excluded. Neuroendocrine carcinomas or double primary tumors were not included. Clinical data, including patient's age, sex, type of surgical treatment, type of adjuvant treatment, survival time, and survival status were reviewed. Pathologic data were obtained from the pathology reports, including tumor location, size, and growth pattern.

\section{Pathologic evaluation}

$\mathrm{T}$ and $\mathrm{N}$ categories of 348 gallbladder cancers were reevaluated by three pathologists (Y.N.S., M.S., and S.M.H.) using the 7th and 8th edition schemes of the AJCC cancer staging system of gallbladder cancer, which are summarized in Table 1 $[9,11]$. Fig. 1 presents representative images in the $\mathrm{T}$ category based on the 8th edition scheme.

Among the 348 patients with gallbladder cancers, 157 without lymph node dissection were excluded from the $\mathrm{N}$ category analysis. Therefore, complete nodal staging data were available for 191 patients of gallbladder cancer. During the analysis, 66 surgically resected gallbladder cancer, with at least six examined lymph nodes, were selected, because the retrieval of a minimum of six lymph nodes is recommended in the 8th edition of the AJCC cancer staging manual for accurate staging [9]. In addition, 125 patients with gallbladder cancer with fewer than six lymph nodes examined were separately evaluated.

Additionally, other histologic features, including histologic subtype, differentiation, invasion depth, lymph nodal metastasis, perineural, lymphovascular, and hepatic invasion, and resection marginal status, were examined.

\section{Statistical analyses}

The SPSS ver. 21.0 software (IBM Corp., Armonk, NY) was used to perform statistical analyses. The unpaired Student's $t$ test was used to perform a comparison of means. Associations between $\mathrm{T}$ and $\mathrm{N}$ categories and other clinicopathologic factors were tested using the chi-square and/or the Fisher exact tests. The overall survival rate was calculated using the Kaplan-Meier method, and significance was evaluated with 
Table 2. Clinicopathologic characteristics

\begin{tabular}{|c|c|}
\hline Characteristic & No. of patients (\%) \\
\hline \multicolumn{2}{|l|}{ Age (yr) } \\
\hline$<60$ & $129(37.1)$ \\
\hline$\geq 60$ & $219(62.9)$ \\
\hline \multicolumn{2}{|l|}{ Sex } \\
\hline Male & $153(44.0)$ \\
\hline Female & $195(56.0)$ \\
\hline \multicolumn{2}{|l|}{ Size (cm) } \\
\hline$<2$ & $67(19.2)$ \\
\hline $2-4$ & $168(48.3)$ \\
\hline$\geq 4$ & $113(32.5)$ \\
\hline \multicolumn{2}{|l|}{ Growth pattern } \\
\hline Infiltrative & $231(66.3)$ \\
\hline Papillary & $58(16.7)$ \\
\hline Nodular & $59(17.0)$ \\
\hline \multicolumn{2}{|l|}{ Histologic type } \\
\hline Pancreatobiliary & $245(70.4)$ \\
\hline Gastric & $22(6.3)$ \\
\hline Intestinal & $27(7.8)$ \\
\hline Combined & $54(15.5)$ \\
\hline \multicolumn{2}{|l|}{ Differentiation } \\
\hline Well & $124(35.6)$ \\
\hline Moderate & $166(47.7)$ \\
\hline Poor & $58(16.7)$ \\
\hline \multicolumn{2}{|l|}{ Location } \\
\hline Fundus & $116(33.3)$ \\
\hline Body & $70(20.1)$ \\
\hline Neck & 47 (13.5) \\
\hline Cystic duct & $12(3.5)$ \\
\hline Diffuse & $103(29.6)$ \\
\hline \multicolumn{2}{|l|}{ T category ${ }^{a)}$} \\
\hline Tis & $4(1.1)$ \\
\hline T1a & $37(10.6)$ \\
\hline $\mathrm{T} 1 \mathrm{~b}$ & $48(13.9)$ \\
\hline $\mathrm{T} 2 \mathrm{a}$ & $106(30.5)$ \\
\hline $\mathrm{T} 2 \mathrm{~b}$ & $69(19.8)$ \\
\hline $\mathrm{T} 3$ & $84(24.1)$ \\
\hline \multicolumn{2}{|l|}{$\mathrm{N}$ categorya) } \\
\hline N0 & $103(54.0)$ \\
\hline N1 & $70(36.6)$ \\
\hline N2 & $18(9.4)$ \\
\hline \multicolumn{2}{|c|}{ Lymphovascular invasion } \\
\hline Present & $90(25.9)$ \\
\hline Absent & $258(74.1)$ \\
\hline \multicolumn{2}{|l|}{ Perineural invasion } \\
\hline Present & $95(27.3)$ \\
\hline Absent & $253(72.7)$ \\
\hline \multicolumn{2}{|l|}{ Margin status } \\
\hline Present & $39(11.2)$ \\
\hline Absent & $309(88.8)$ \\
\hline
\end{tabular}

(Continued)
Table 2. Continued

\begin{tabular}{cr} 
Characteristic & No. of patients (\%) \\
Liver invasion & \\
Present & $42(12.1)$ \\
Absent & $306(87.9)$ \\
\hline
\end{tabular}

a) 8 th edition scheme of the American Joint Committee on Cancer cancer staging system.

the log-rank test. The Cox proportional hazards regression model was used to investigate the significance of $\mathrm{T}$ and $\mathrm{N}$ categories as prognostic factors. $\mathrm{p}<0.05$ was considered statistically significant.

\section{Ethical statement}

The Institutional Review Board of Asan Medical Center approved this study (No. 2019-0142) with a waiver of the informed consent.

\section{Results}

\section{Clinicopathologic characteristics}

Table 2 summarizes the characteristics of selected cases. The mean age of the patients was $62.9 \pm 10.3$ years (range, 32 to 89 years). A total of 153 patients $(44.0 \%)$ were men, and $195(56.0 \%)$ were women. Tumors were located in the fundus in $116(33.3 \%)$, body in $70(20.1 \%)$, neck in $47(13.5 \%)$, cystic duct in $12(3.5 \%)$, and diffuse pattern in 103 cases $(29.6 \%)$. The tumors showed an infiltrative pattern in $231(66.3 \%)$, papillary in $58(16.7 \%)$, and nodular in $59(17.0 \%)$ patients. The mean tumor size was $3.3 \pm 2.4 \mathrm{~cm}$. Based on the histologic subtype, 245 were pancreatobiliary $(70.4 \%), 22$ gastric $(6.3 \%)$, 27 intestinal $(7.8 \%)$, and 54 combined (15.5\%) types. A total of 124 tumors (35.6\%) were well differentiated, 166 (47.7\%) moderately differentiated, and $58(16.7 \%)$ poorly differentiated. Based on the 8th edition scheme, four carcinomas were in situ (Tis, 1.1\%), 37 T1a (10.6\%), 48 T1b (13.9\%), 106 T2a (30.5\%), 69 T2b (19.8\%), and $84 \mathrm{~T} 3(24.1 \%)$. However, no T4 was observed, because all cases were surgically resected. Based on surgical treatment, $142(40.8 \%)$ had simple cholecystectomy, 15 (4.3\%) simple cholecystectomy with bile duct resection, 152 (43.7\%) extended cholecystectomy, 35 (10.1\%) extended cholecystectomy with bile duct resection, and four $(1.1 \%)$ cholecystectomy with pylorus preserving pancreaticoduodenectomy. 


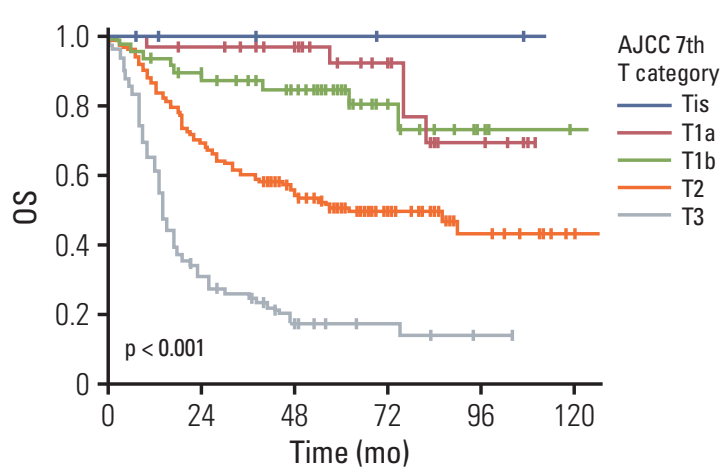

A

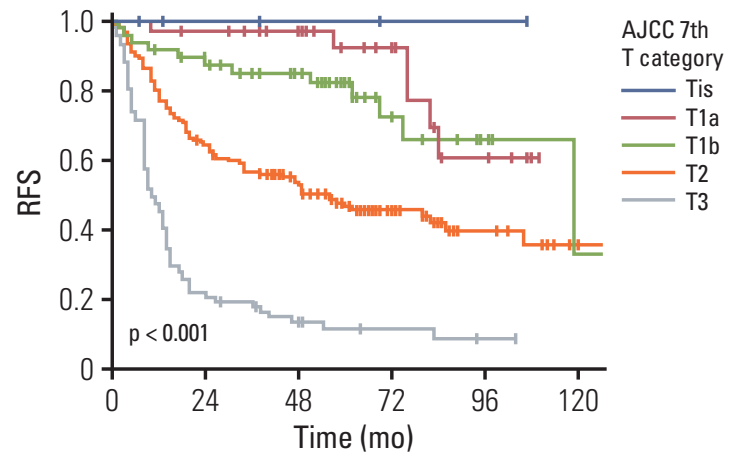

B

C
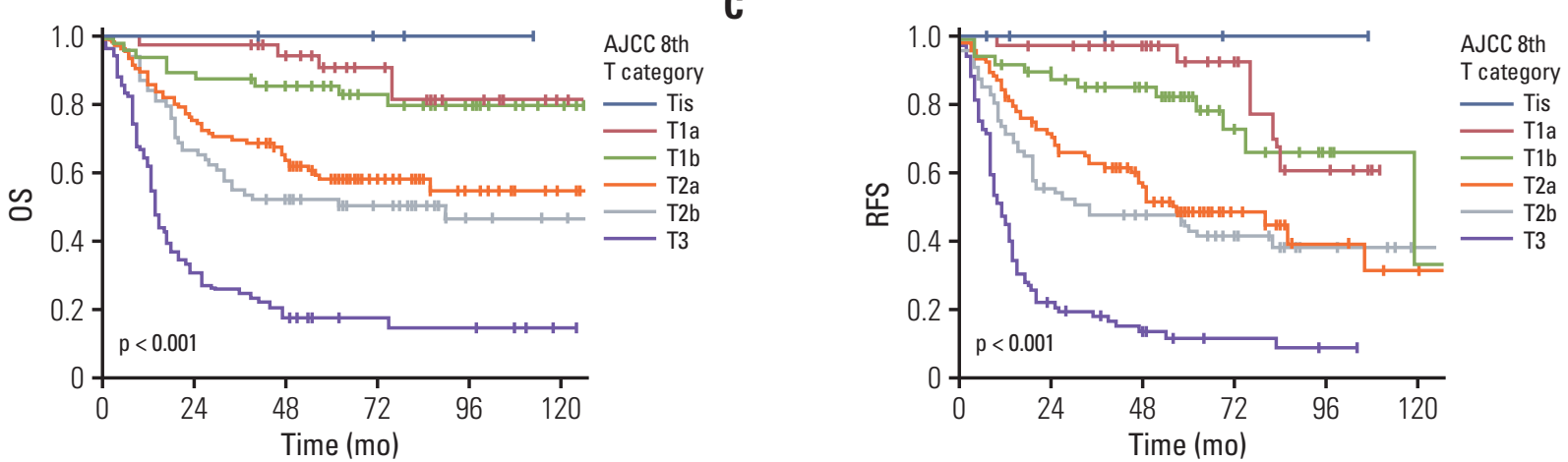

D

E
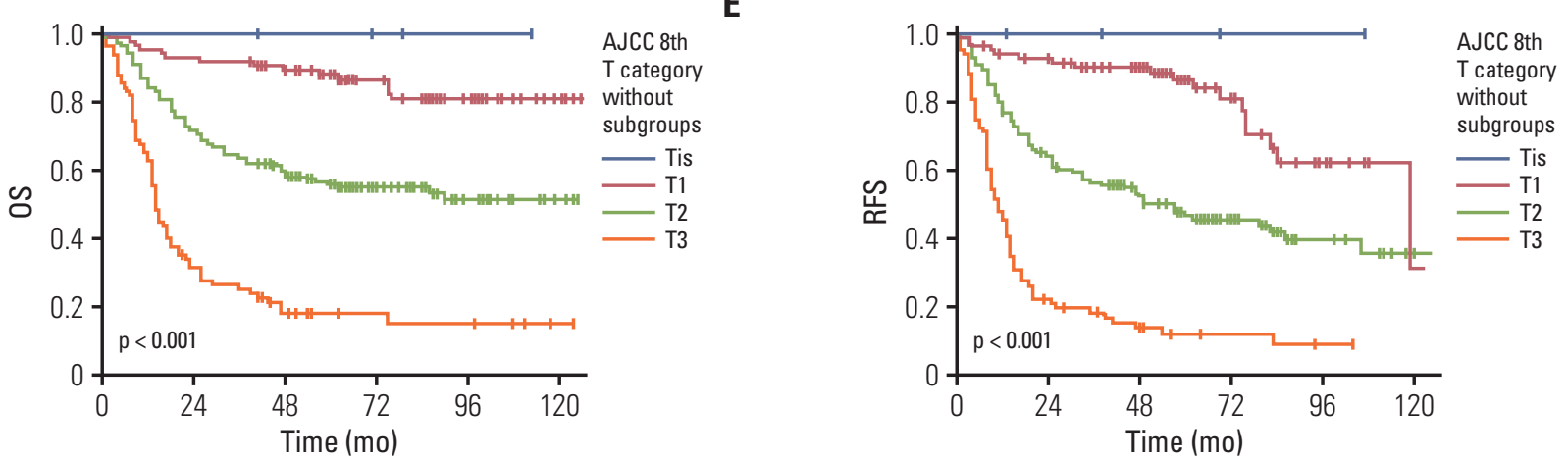

Fig. 2. The overall (OS) and recurrence-free survival (RFS) according to the $\mathrm{T}$ categories of the 7th and 8th American Joint Committee on Cancer (AJCC) staging system scheme. The OS (A) and RFS (B) in patients with gallbladder cancer according to the $\mathrm{T}$ category of the 7th edition; significant differences were observed in the overall $(\mathrm{p}<0.001)$ and pair-wise comparisons between T1b-T2 ( $\mathrm{p}=0.001)$ and T2-T3 $(\mathrm{p}<0.001)$ tumors, except for Tis-T1a $(\mathrm{p}=0.482)$ and T1a-T1b $(\mathrm{p}=0.387)$ lesions. The OS (C) and RFS (D) of patients with gallbladder cancer according to the T category in the 8th edition; significant differences were observed in the OS in overall comparisons $(\mathrm{p}<0.001)$ and pair-wise comparisons between T1b-T2a $(\mathrm{p}=0.003)$ and T2bT3 $(\mathrm{p}<0.001)$ tumors. The OS (E) and RFS (F) of patients with gallbladder cancer according to the T category in the 8th edition without subdivision; significant differences were observed in the OS in overall $(\mathrm{p}<0.001)$ and pair-wise comparisons between T1-T2 $(\mathrm{p}<0.001)$ and T2-T3 $(\mathrm{p}<0.001)$ tumors.

Among the 66 evaluated cases with at least six examined lymph nodes, 28 were N0 (42.4\%), $22 \mathrm{~N} 1(33.3 \%)$, and $16 \mathrm{~N} 2$ $(24.3 \%)$ tumors, respectively, according to the $\mathrm{N}$ category. Lymphovascular, perineural, and liver invasion was identi- fied in $90(25.9 \%), 95(27.3 \%)$, and $42(12.1 \%)$ patients, respectively. The median follow-up period was 51.5 months (range, 2 to 131 months). The median survival of all patients was 75 months. The 1-, 3-, and 5-year survival rates were $81.5 \%$, 
$59.2 \%$, and $51.9 \%$, respectively. One hundred nineteen of 259 patients (45.9\%) with more than T2 classification had adjuvant chemotherapy or concurrent chemoradiation therapy with preferably capecitabine (41 patients), 5-fluorouracil (18 patients), or both (1 patient) based on guidelines of the Korean Association of Hepato-Biliary and Pancreas Surgery [13]. In addition, tegafur/gimeracil/oteracil (S-1, 18 patients) or gemcitabine/ cisplatin (16 patients) were used. Irinotecan, docetaxel, oxaliplatin, and erlotinib were additionally used in some cases. Chemotherapeutic regimens were unknown for 25 patients, who transferred to primary hospitals for adjuvant chemotherapy after surgery.

\section{Patient survival according to the $T$ category}

Based on the 7th edition schemes, 4 had Tis (1.1\%), $37 \mathrm{~T} 1$ (10.6\%), $48 \mathrm{~T} 1 \mathrm{~b}(13.8 \%), 175 \mathrm{~T} 2(50.3 \%)$, and $84 \mathrm{~T} 3(24.1 \%)$.

When we compared patients' survival time based on the previous 7th edition scheme of the $\mathrm{T}$ category, the 5-year overall survival rate in patients with gallbladder cancer with Tis, T1a, T1b, T2, and T3 was 100\%, 92.4\%, 84.8\%, 50.4\%, and $17.3 \%$, respectively (overall comparison, $\mathrm{p}<0.001$ ) (Fig. 2A). In fact, significant differences in the overall survival were observed in the pair-wise comparisons of $\mathrm{T} 1 \mathrm{~b}-\mathrm{T} 2(\mathrm{p}=0.001)$ and T2-T3 $(\mathrm{p}<0.001)$ lesions. However, no difference in the overall survival was observed in the comparisons of Tis-T1a $(\mathrm{p}=0.482)$ and T1a-T1b ( $\mathrm{p}=0.387)$ lesions. Similarly, the 5-year recurrence-free survival rate in patients with gallbladder cancer with Tis, T1a, T1b, T2, and T3 was 100\%, 92.4\%, 82.3\%, $46.8 \%$, and $11.5 \%$, respectively (overall comparison, $\mathrm{p}<0.001$ ) (Fig. 2B). Significant differences in the recurrence-free survival were observed in the pair-wise comparisons of T1b-T2 $(\mathrm{p}=0.001)$ and T2-T3 $(\mathrm{p}<0.001)$ lesions. However, no difference in the overall survival was observed in the comparisons of Tis-T1a $(\mathrm{p}=0.431)$ and T1a-T1b $(\mathrm{p}=0.321)$ lesions.

Using the T category criteria of the 8th edition, four carcinoma in situ (Tis, 1.1\%), 37 T1a (10.6\%), 48 T1b (13.9\%), 106 T2a (30.5\%), 69 T2b (19.8\%), and 84 T3 (24.1\%) were observed. The overall 5 -year survival rate in patients with gallbladder cancer with Tis, T1a, T1b, T2a, T2b, and T3 was $100 \%, 92.4 \%, 84.8 \%, 52.4 \%, 47.3 \%$, and $17.1 \%$, respectively (overall comparison, $\mathrm{p}<0.001$ ) (Fig. 2C). A significant difference in the overall survival was observed in pair-wise comparisons of T1b-T2a $(\mathrm{p}=0.003)$ and T2b-T3 $(\mathrm{p}<0.001)$ lesions. However, no survival difference was observed between TisT1a $(\mathrm{p}=0.482)$, T1a-T1b $(\mathrm{p}=0.387)$, and T2a-T2b $(\mathrm{p}=0.223)$ lesions. Similarly, the 5-year recurrence-free survival rate in patients with gallbladder cancer with Tis, T1a, T1b, T2a, T2b and T3 was $100 \%, 92.4 \%, 82.3 \%, 48.3 \%, 43.6 \%$, and $11.5 \%$, respectively (overall comparison, $\mathrm{p}<0.001$ ) (Fig. 2D). A significant difference in the recurrence-free survival was observed in pair-wise comparisons of T1b-T2a $(\mathrm{p}=0.003)$ and $\mathrm{T} 2 \mathrm{~b}-\mathrm{T} 3$ $(\mathrm{p}<0.001)$ lesions. However, no survival difference was observed between Tis-T1a ( $\mathrm{p}=0.431), \mathrm{T} 1 \mathrm{a}-\mathrm{T} 1 \mathrm{~b}(\mathrm{p}=0.321)$, and $\mathrm{T} 2 \mathrm{a}-\mathrm{T} 2 \mathrm{~b}(\mathrm{p}=0.364)$ lesions.

When additional survival analysis was performed based on the 8th AJCC staging scheme without dividing T1 and T2 subcategories, the overall 5-year survival rate in patients with gallbladder cancer with Tis, T1, T2, and T3 was $100 \%$, $88.8 \%, 50.4 \%$, and $17.3 \%$ respectively. Significant overall survival differences were observed both by the overall $(p<$ 0.001 ) and pair-wise (T1-T2, $\mathrm{p}<0.001$; T2-T3, $\mathrm{p}<0.001$ ) comparisons (Fig. 2E). Similarly, the 5-year recurrence-free survival rate in patients with gallbladder cancer with Tis, T1, T2, and $\mathrm{T} 3$ was $100 \%, 84.1 \%, 45.7 \%$, and $11.5 \%$, respectively. Significant recurrence-free survival differences were observed both by the overall $(\mathrm{p}<0.001)$ and pair-wise $(\mathrm{T} 1-\mathrm{T} 2, \mathrm{p}<$ 0.001; T2-T3, $\mathrm{p}<0.001$ ) comparisons (Fig. 2F).

\section{Patient survival according to the $\mathrm{N}$ category}

Among the 348 patients with gallbladder cancers, $157 \mathrm{did}$ not perform lymph node dissection and were classified as NX. The N category analysis was performed on a total of 348 patients, including $157 \mathrm{NX}$ cases.

When we compared patients' survival time based on the previous 7 th edition scheme, the overall 5-year survival rate in patients with gallbladder cancer with $\mathrm{N} 0, \mathrm{~N} 1$, and $\mathrm{N} 2$ was $69.8 \%, 21.9 \%$, and $0 \%$, respectively. The overall 5-year survival rate in patients with gallbladder cancer with $\mathrm{NX}$ was $53.8 \%$. A significant difference in the overall survival was observed in gallbladder cancers (overall comparison, $\mathrm{p}<$ 0.001) (Fig. 3A). A significant difference was observed in the pair-wise comparisons of N0-N1 ( $p<0.001)$ lesions, but not in the comparisons of N1-N2 lesions ( $\mathrm{p}=0.416$ ). Similarly, the 5 -year recurrence-free survival rate in patients with gallbladder cancer with $\mathrm{N} 0, \mathrm{~N} 1$, and $\mathrm{N} 2$ was $66.0 \%, 19.8 \%$, and $0 \%$, respectively. The 5-year recurrence-free survival rate in patients with gallbladder cancer with NX was $52.9 \%$. A significant difference in the recurrence-free survival was observed in gallbladder cancers (overall comparison, $\mathrm{p}<0.001$ ) (Fig. 3B). A significant difference was observed in the pair-wise comparisons of N0-N1 $(\mathrm{p}<0.001)$, but not in the comparisons of $\mathrm{N} 1-\mathrm{N} 2(\mathrm{p}=0.238)$.

When we compared patients' survival time based on the current 8th edition scheme of the $\mathrm{N}$ category including 157 NX cases, the overall 5-year survival rate in patients with gallbladder cancer with N0, N1, and N2 was $69.8 \%, 20.0 \%$ and $0 \%$, respectively (overall comparison, $\mathrm{p}<0.001$ ) (Fig. 3C). A significant difference in the overall survival was also observed in the pair-wise comparisons of N0-N1 ( $<<0.001)$, but not in the comparisons of N1-N2 lesions ( $p=0.238)$. Significant differences in the overall survival were also observed in the pair-wise comparisons between N0-NX ( $\mathrm{p}=0.001)$ and 
A

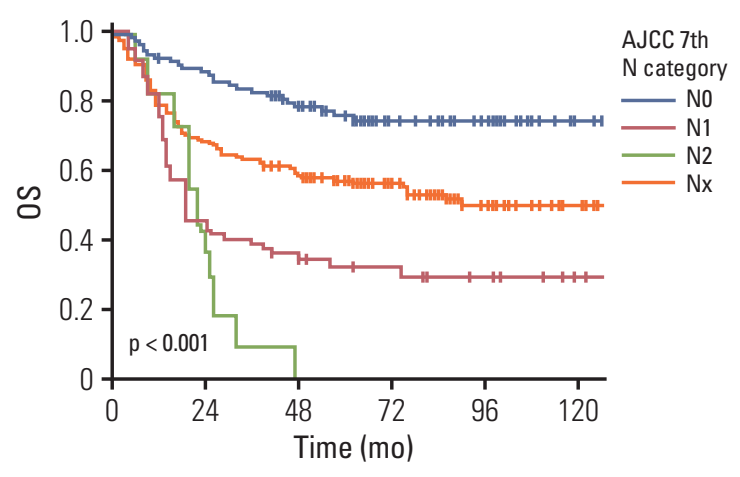

C

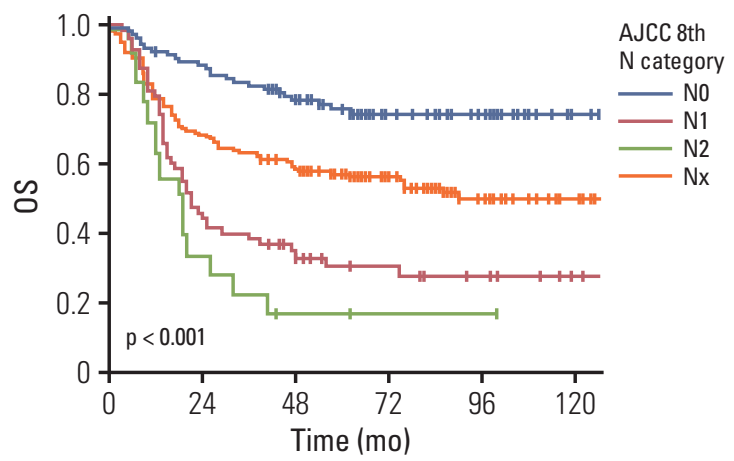

B

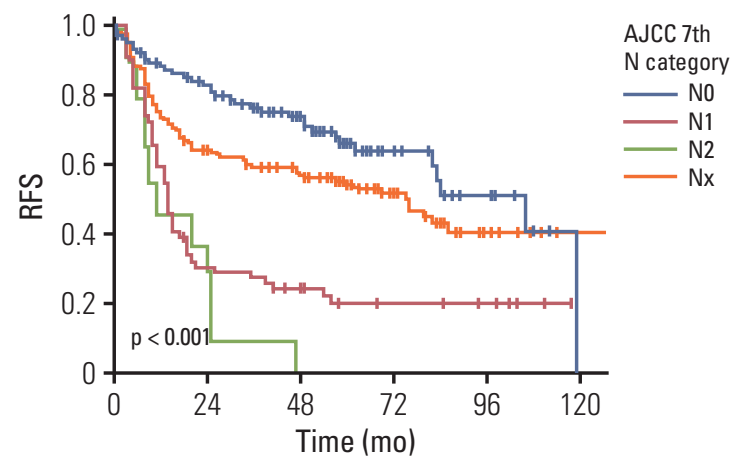

D

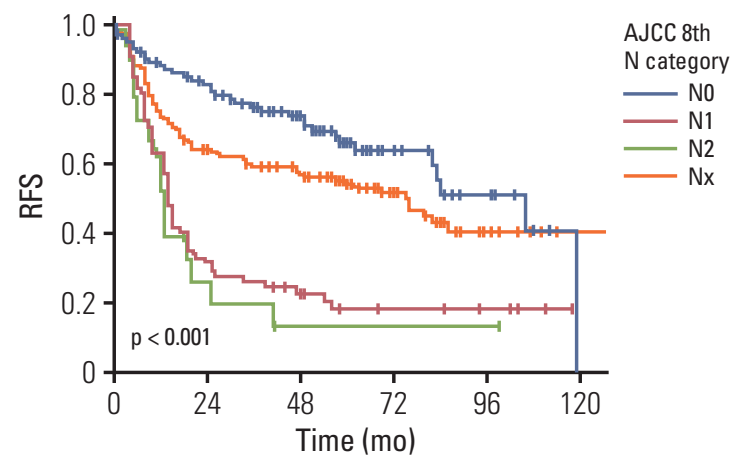

Fig. 3. The overall (OS) and recurrence-free survival (RFS) according to N categories of the 7th and 8th American Joint Committee on Cancer (AJCC) staging system scheme including patients without lymph node dissection as NX. The OS (A) and RFS (B) of patients with gallbladder cancer according to the $\mathrm{N}$ category of the 7th edition including NX. A significant difference was also observed in overall comparisons $(\mathrm{p}<0.001)$ and pair-wise comparisons of N0-N1 $(\mathrm{p}<0.001)$ lesions. The OS (C) and RFS (D) of patients with gallbladder cancer according to the $\mathrm{N}$ category in the 8th edition including NX. A significant difference was observed in overall ( $\mathrm{p}<0.001)$ and pair-wise comparisons of N0-N1 $(\mathrm{p}<0.001), \mathrm{N} 0-\mathrm{NX}(\mathrm{p}=0.001)$, and NX$\mathrm{N} 1(\mathrm{p}<0.001)$.

NX-N1 ( $<$ 0.001). Similarly, the 5-year recurrence-free survival rate in patients with gallbladder cancer with N0, N1, and $\mathrm{N} 2$ was $66.0 \%, 17.9 \%$, and $0 \%$, respectively. The 5 -year recurrence-free survival rate in patients with gallbladder cancer with NX was $52.9 \%$. A significant difference in the recurrence-free survival was observed in gallbladder cancers (overall comparison, $\mathrm{p}<0.001$ ) (Fig. 3D). A significant difference was observed in the pair-wise comparisons of N0-N1 $(\mathrm{p}<0.001)$ and NX-N1 $(\mathrm{p}<0.001)$ lesions, but not in the comparisons of N1-N2 ( $\mathrm{p}=0.474)$ and N0-NX $(\mathrm{p}=0.051)$.

\section{Patient survival according to the $\mathrm{N}$ category with $\geq 6$ examined lymph nodes}

Among the 191 cases with lymph node dissection, 66 were examined more than or equal to six examined lymph nodes, whereas 125 were examined with $<6$ examined lymph nodes.

First, when we performed the subgroup survival analysis in 66 patients with $\geq 6$ examined lymph nodes following the 8 th edition recommendation. When we compared patients' survival time based on the previous 7 th edition scheme, the overall 5-year survival rate in patients with gallbladder cancer with $\mathrm{N} 0, \mathrm{~N} 1$, and $\mathrm{N} 2$ was $72.2 \%, 23.2 \%$, and $0 \%$, respectively (overall comparison, $\mathrm{p}<0.001$ ) (Fig. 4A). A significant difference was observed in the pair-wise comparisons of N0$\mathrm{N} 1(\mathrm{p}<0.001)$ lesions, but not in the comparisons of N1-N2 lesions ( $\mathrm{p}=0.459)$. Similarly, the 5 -year recurrence-free survival rate in patients with gallbladder cancer with N0, N1, and $\mathrm{N} 2$ was $64.6 \%, 16.9 \%$, and $0 \%$, respectively (overall comparison, $\mathrm{p}<0.001$ ) (Fig. 4B). A significant difference was observed in the pair-wise comparison of N0-N1 $(p<0.001)$ lesions, but not in the comparison of N1-N2 lesions ( $\mathrm{p}=0.566$ ).

When we compared 66 patients' survival time based on the current 8 th edition scheme in the $\mathrm{N}$ category with $\geq 6$ examined lymph nodes, the overall 5-year survival rate in patients with gallbladder cancer with N0, N1, and N2 was $72.2 \%$, 
A
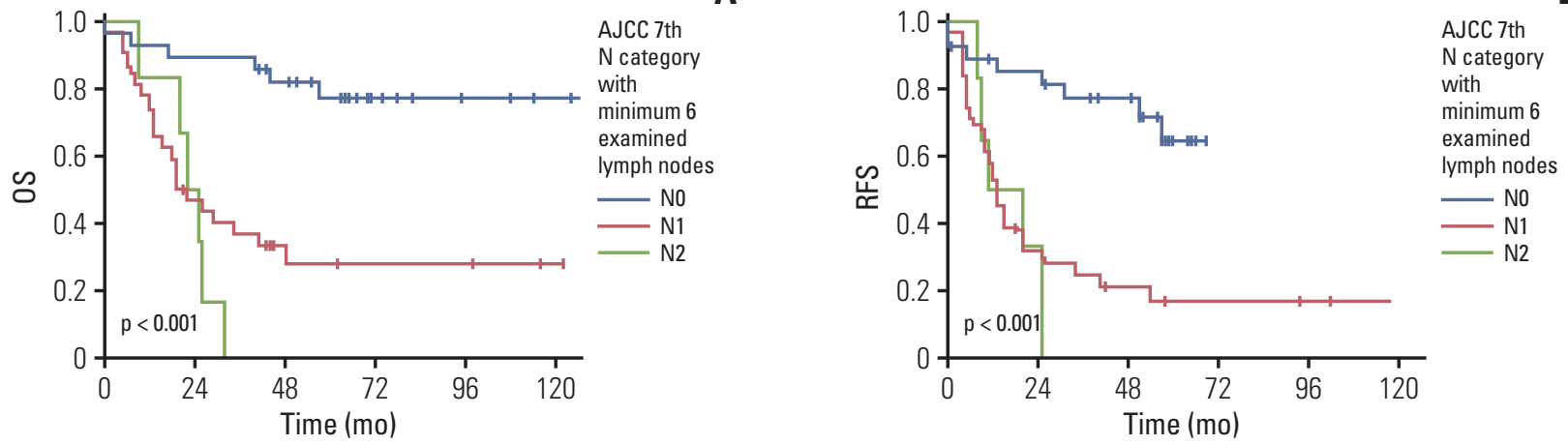

B
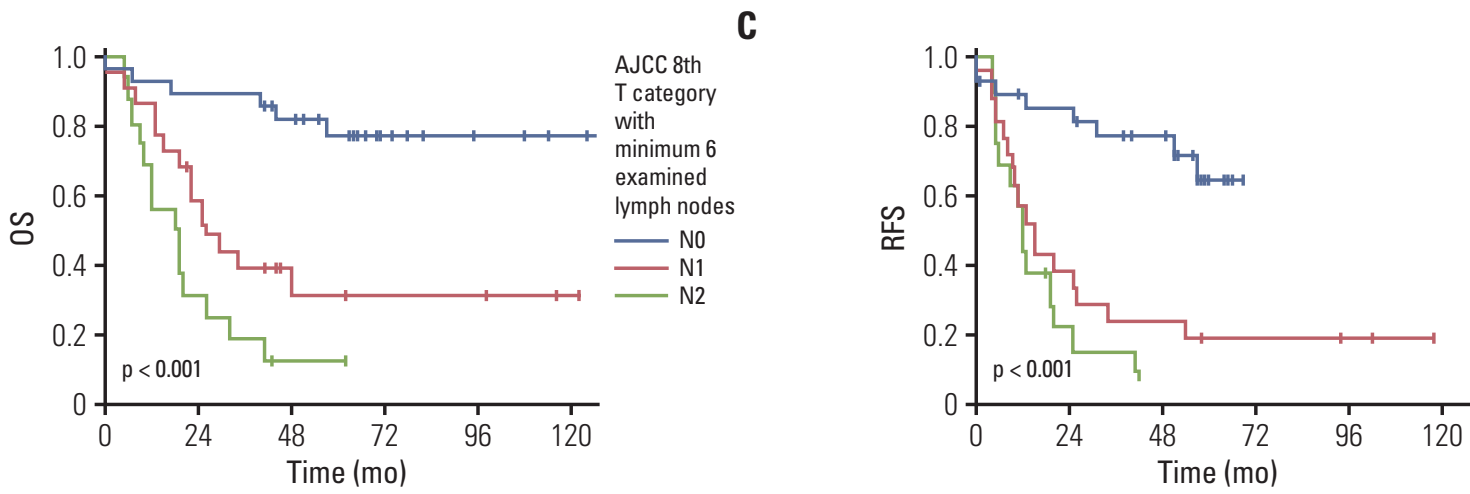

AJCC 8th

T category

with

minimum 6

examined

lymph nodes

NO

N1

E
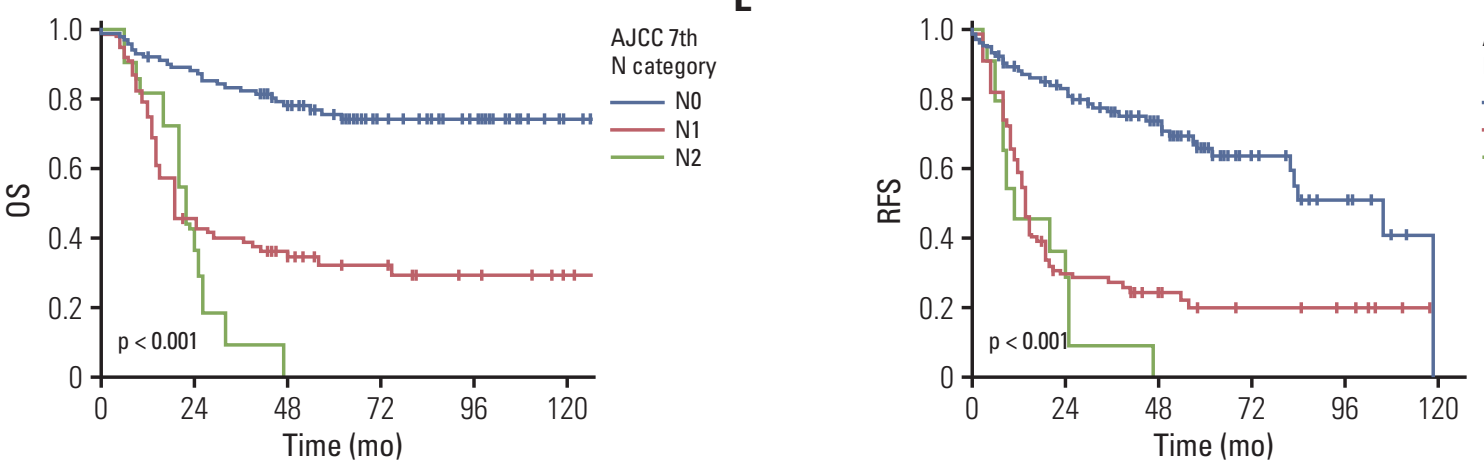

D

Fig. 4. The overall (OS) and recurrence-free survival (RFS) according to N categories of the 7th and 8th editions of the American Joint Committee on Cancer (AJCC) staging system scheme based on number of examined lymph nodes. The OS (A) and RFS (B) in patients with gallbladder cancer according to the $\mathrm{N}$ category of the 7 th edition scheme with $\geq 6$ examined lymph nodes. A significant difference was observed in overall $(\mathrm{p}<0.001)$ and pair-wise comparisons of N0-N1 ( $p<0.001)$ lesions. The OS (C) and RFS (D) of patients with gallbladder cancer according to the $\mathrm{N}$ category of the 8th edition scheme with $\geq 6$ examined lymph nodes. A significant difference was noted in OS in overall $(\mathrm{p}<0.001)$ and pair-wise comparisons of N0-N1 ( $p=0.001)$ and N1-N2 ( $p=0.039$ ) lesions. The OS (E) and RFS (F) of patients with gallbladder cancer according to the $\mathrm{N}$ category of the 7th edition in a subgroup with 1-5 examined lymph nodes. A significant difference was observed in overall ( $\mathrm{p}<0.001)$ and pair-wise comparisons of N0-N1 $(\mathrm{p}<0.001)$. (Continued to the next page)

$28.8 \%$, and $7.1 \%$, respectively (overall comparison, $\mathrm{p}<0.001$ ) (Fig. 4C). A significant difference in the overall survival was observed both in pair-wise comparisons of N0-N1 ( $p=0.001$ ) and N1-N2 ( $p=0.039)$ lesions. Similarly, the 5-year recur- rence-free survival rate in patients with gallbladder cancer with N0, N1, and N2 was $64.6 \%, 19.1 \%$, and $0 \%$, respectively (overall comparison, $\mathrm{p}<0.001$ ) (Fig. 4D). A significant difference was observed in the pair-wise comparison of N0-N1 
G
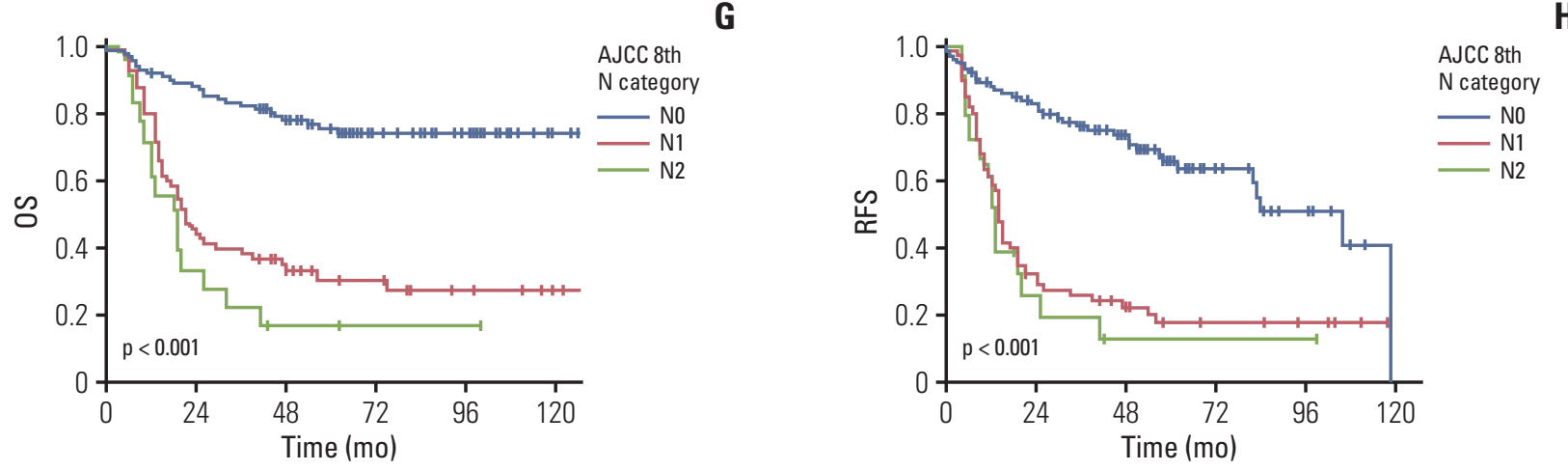

Fig. 4. (Continued from the previous page) The OS (G) and RFS (H) of patients with gallbladder cancer according to the $\mathrm{N}$ category of the 8th edition in a subgroup with 1-5 examined lymph nodes. A significant difference in the OS was observed in overall ( $\mathrm{p}<0.001)$ and pair-wise comparisons of N0-N1 $(\mathrm{p}<0.001)$.

$(\mathrm{p}<0.001)$ lesions, but not in the comparison of N1-N2 lesions $(\mathrm{p}=0.311)$.

\section{Patient survival according to the $\mathrm{N}$ category with 1-5 examined lymph nodes}

Additionally, we compared 125 patients' survival time with 1-5 examined lymph nodes, because several incidentally detected gallbladder cancer cases did not meet the recommended cut-off number of lymph nodes. When we compared patients' survival time based on the previous 7 th edition scheme, the overall 5-year survival rate in patients with gallbladder cancer with N0, N1, and N2 was $75.0 \%$, $34.0 \%$, and $0 \%$, respectively (overall comparison, $p<0.001$ ) (Fig. 4E). A significant difference was observed in pair-wise comparisons of N0-N1 $(\mathrm{p}<0.001)$, but not in the comparisons of N1-N2 ( $p=0.349)$ lesions. Similarly, the 5-year survival recurrence-free survival rate in patients with gallbladder cancer with N0, N1, and N2 was $63.3 \%, 22.2 \%$, and $0 \%$, respectively (overall comparison, $\mathrm{p}<0.001$ ) (Fig. $4 \mathrm{~F}$ ). A significant difference was observed in pair-wise comparison of N0-N1 $(\mathrm{p}<0.001)$, but not in the comparison of N1-N2 $(\mathrm{p}=0.240)$ lesions.

When we compared 125 patients' survival time based on the current 8 th edition scheme of the $\mathrm{N}$ category with 1-5 examined lymph nodes, the overall 5-year survival rate in patients with gallbladder cancer with N0, N1, and N2 was $73.0 \%, 29.2 \%$, and $50 \%$, respectively (overall comparison, $\mathrm{p}<0.001$ ) (Fig. 4G). A significant difference in the overall survival was also observed in pair-wise comparisons of N0-N1 $(\mathrm{p}<0.001)$, but not in the comparisons of N1-N2 $(\mathrm{p}=0.624)$ lesions. Similarly, the 5-year recurrence-free survival rate in patients with gallbladder cancer with N0, N1, and N2 was $63.3 \%, 17.3 \%$, and $50 \%$, respectively (overall comparison, $\mathrm{p}<0.001$ ) (Fig. 4H). A significant difference was observed in pair-wise comparison of N0-N1 ( $<<0.001)$, but not in the comparison of N1-N2 ( $\mathrm{p}=0.430)$ lesions.

\section{Patient survival according to stage grouping}

Among the 348 patients with gallbladder cancers, 157 without lymph node dissection were excluded for the stage group analysis. Therefore, complete stage group data were available in 191 patients with gallbladder cancer. Based on the 7 th edition stage schemes, 39 had stage I (20.4\%), 48 stage II $(25.1 \%), 16$ stage IIIA $(8.4 \%), 70$ stage IIIB $(36.6 \%)$, and 18 stage IVB $(9.4 \%)$. As only surgically resected patients were included, stage IVA was not observed. When we compared patients' survival time based on the previous 7th edition scheme of the stage grouping, the overall 5-year survival rate in patients with gallbladder cancer with stages I, II, IIIA, IIIB, and IVB was $78.4 \%, 73.6 \% 39.7 \%, 20.0 \%$, and $12.5 \%$, respectively (overall comparison, $p<0.001$ ) (Fig. 5A). Significant differences in the overall 5-year survival rate were observed in the pair-wise comparisons between stage II and IIIA ( $\mathrm{p}<$ $0.009)$, but not between stages I-II $(\mathrm{p}=0.349)$, IIIA-IIIB $(\mathrm{p}=0.137)$, and IIIB-IVB $(\mathrm{p}=0.238)$. Similarly, the 5 -year recurrence-free survival rate in patients with gallbladder cancer with stages I, II, IIIA, IIIB, and IVB was $75.4 \%, 64.1 \%, 32.7 \%$, $17.9 \%$, and $12.5 \%$, respectively (overall comparison, $\mathrm{p}<$ 0.001 ) (Fig. 5B). Significant differences in the recurrence-free survival were observed in the pair-wise comparisons between stage II and IIIA ( $p=0.001$ ), but not between stages I-II $(p=0.096)$, IIIA-IIIB $(p=0.624)$, and IIIB-IVB $(p=0.474)$. When comparing the stage grouping without the substages, significant differences in the overall 5 -year survival rate were observed in the overall comparison $(p<0.001)$ and in the pair-wise comparisons between stages II and III $(\mathrm{p}<0.001)$. 
A

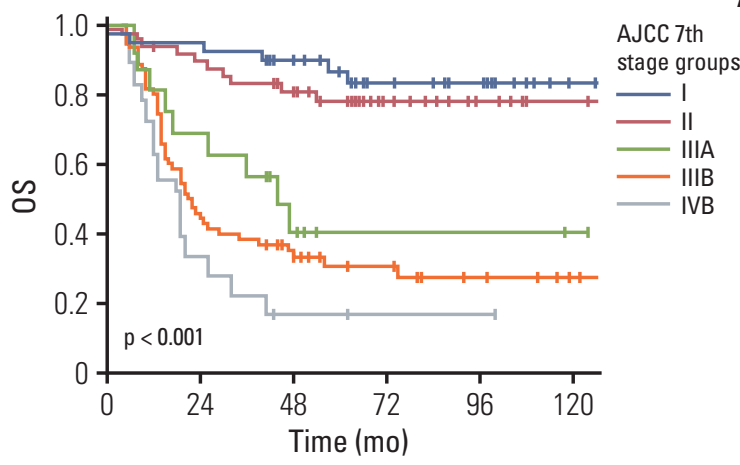

C

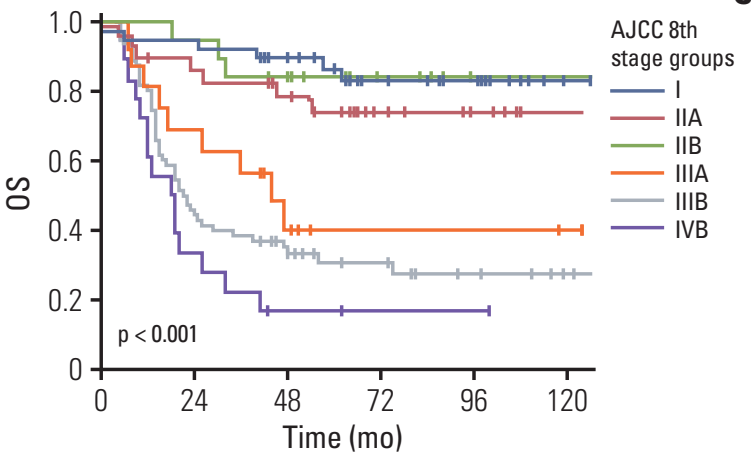

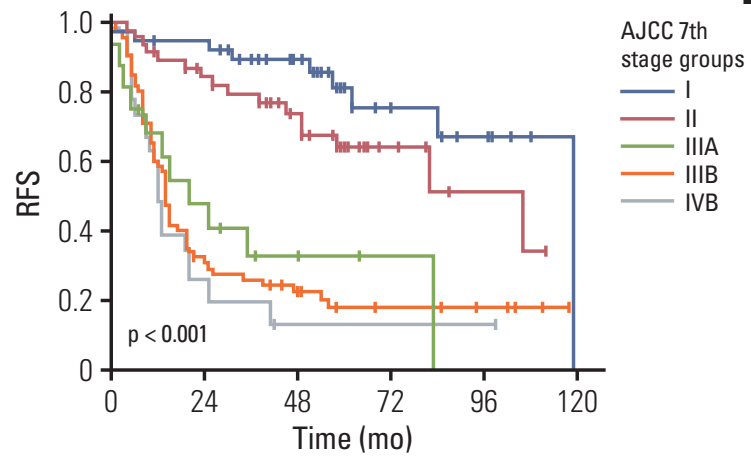

D

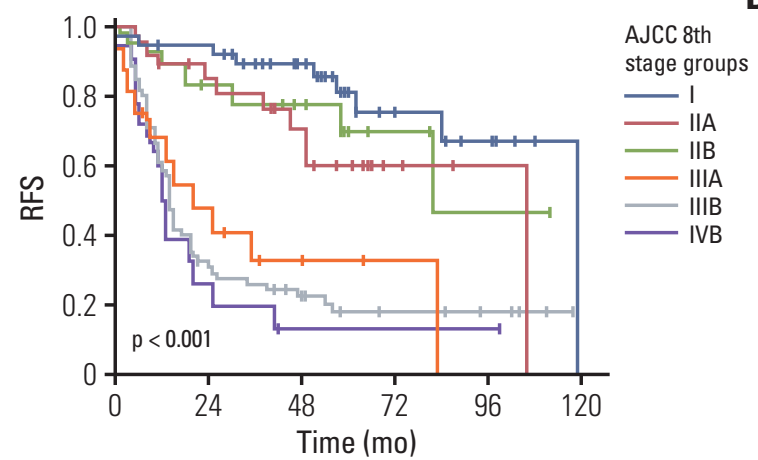

Fig. 5. The overall (OS) and recurrence-free survival (RFS) according to stage grouping of the 7th and 8th editions of the American Joint Committee on Cancer (AJCC) staging system. The OS (A) and RFS (B) of patients with gallbladder cancer according to the stage grouping of the 7th edition scheme; significant differences in the OS were observed in overall comparisons ( $p<0.001$ ) and the pair-wise comparisons of stages II and IIIA ( $p=0.009)$. The OS (C) and RFS (D) of patients with gallbladder cancer according to the stage grouping of the 8th edition scheme; significant differences in the OS were observed in overall $(\mathrm{p}<0.001)$ and the pair-wise comparisons between stage IIB and IIIA $(\mathrm{p}=0.018)$.

However, no significant difference was observed in the 5 -year survival rate of pair-wise comparisons of I-II $(\mathrm{p}=0.349)$, III-IV ( $\mathrm{p}=0.111)$.

Based on the 8th edition stage schemes, 39 patients were in stage I (20.4\%), 29 stage IIA (15.2\%), 19 stage IIB (9.9\%), 16 stage IIIA (8.4\%), 70 stage IIIB $(36.6 \%)$, and 18 stage IVB $(9.4 \%)$. Based on the 8 th edition schemes, the overall 5-year survival rate in patients with gallbladder cancer with stages I, IIA, IIB, IIIA, IIIB, and IVB was 78.4\%, 68.7\%, 81.6\%, 39.7\%, $20.0 \%$, and $12.5 \%$, respectively. Significant differences in the 5 -year survival rate were observed in the pair-wise comparisons between stages IIB and IIIA only ( $\mathrm{p}=0.018)$. However, no significant difference was observed in the 5-year survival rate of pair-wise comparisons between stages I-IIA ( $\mathrm{p}=0.240)$, IIA-IIB ( $\mathrm{p}=0.456)$, IIIA-IIIB ( $\mathrm{p}=0.137)$, and IIIB-IVB $(\mathrm{p}=0.238)$ (Fig. 5C). Similarly, the 5-year recurrence-free survival rate in patients with gallbladder cancer with stages I, IIA, IIB, IIIA, IIIB, and IVB was $75.4 \%, 60.1 \%, 69.9 \%, 32.7 \%, 17.9 \%$, and $12.5 \%$, respectively. Significant differences in the recur- rence-free survival rate were observed in the pair-wise comparisons between stages IIB and IIIA only $(\mathrm{p}=0.011)$. However, no significant difference was observed in the recurrence-free survival rate of pair-wise comparisons between stages I-IIA ( $\mathrm{p}=0.079)$, IIA-IIB ( $\mathrm{p}=0.532)$, IIIA-IIIB ( $\mathrm{p}=0.624)$, and IIIB-IVB ( $p=0.474)$ (Fig. 5D). When comparing the stage grouping without dividing the substages, significant differences in the overall 5-year survival rate were observed in the overall comparison $(p<0.001)$ and in the pair-wise comparisons between stages II and III ( $p<0.001)$. However, no significant difference was observed in the 5-year survival rate of pair-wise comparisons between stages I-II $(\mathrm{p}=0.349)$ and III-IV ( $\mathrm{p}=0.111)$.

\section{Patient survival according to other clinicopathologic fac- tors}

A number of other clinicopathologic factors were associated with the overall survival on univariate analyses (Table 3). 
Table 3. Univariate and multivariate analyses of clinicopathologic features affecting patients survival with gallbladder cancer

\begin{tabular}{|c|c|c|c|c|c|c|}
\hline \multirow[b]{2}{*}{ Variable } & \multirow[b]{2}{*}{$\begin{array}{c}\text { No. of } \\
\text { patients }\end{array}$} & \multicolumn{2}{|c|}{ Univariate analysis } & \multicolumn{3}{|c|}{ Multivariate analysis } \\
\hline & & $\begin{array}{c}\text { 5-Year } \\
\text { survival (\%) }\end{array}$ & p-value & $\begin{array}{l}\text { Hazard } \\
\text { ratio }\end{array}$ & $\begin{array}{c}95 \% \\
\text { Confidence } \\
\text { interval }\end{array}$ & p-value \\
\hline
\end{tabular}

\begin{tabular}{|c|c|c|c|c|c|c|}
\hline \multicolumn{7}{|l|}{ Age (yr) } \\
\hline$<60$ & 129 & 56.6 & 0.068 & & & \\
\hline$\geq 60$ & 219 & 47.0 & & & & \\
\hline \multicolumn{7}{|l|}{ Sex } \\
\hline Male & 153 & 54.4 & 0.660 & & & \\
\hline Female & 195 & 48.8 & & & & \\
\hline \multicolumn{7}{|l|}{ Size $(\mathrm{cm})$} \\
\hline$<2$ & 67 & 68.8 & $<0.001^{\mathrm{a})}$ & 1.451 & $0.975-2.159$ & 0.066 \\
\hline $2-4$ & 168 & 50.6 & & & & \\
\hline$\geq 4$ & 113 & 39.9 & & & & \\
\hline \multicolumn{7}{|l|}{ Growth pattern } \\
\hline Infiltrative & 231 & 42.1 & $<0.001^{\mathrm{a})}$ & 0.718 & $0.485-1.064$ & 0.099 \\
\hline Papillary & 58 & 67.9 & & & & \\
\hline Nodular & 59 & 70.2 & & & & \\
\hline \multicolumn{7}{|l|}{ Histologic type } \\
\hline Pancreatobiliary & 245 & 48.4 & 0.324 & & & \\
\hline Gastric & 22 & 55.4 & & & & \\
\hline Intestinal & 27 & 43.5 & & & & \\
\hline Combined & 54 & 49.6 & & & & \\
\hline \multicolumn{7}{|l|}{ Differentiation } \\
\hline Well & 124 & 78.1 & $<0.001^{\text {a) }}$ & 1.069 & $0.731-1.561$ & 0.732 \\
\hline Moderately & 166 & 35.4 & & & & \\
\hline Poorly & 58 & 31.9 & & & & \\
\hline \multicolumn{7}{|l|}{ T, AJCC 8th ed. } \\
\hline Tis & 4 & 100 & $<0.001^{\mathrm{a})}$ & 1.376 & $1.059-1.787$ & $0.017^{\mathrm{a})}$ \\
\hline T1a & 37 & 92.4 & & & & \\
\hline $\mathrm{T} 1 \mathrm{~b}$ & 48 & 84.8 & & & & \\
\hline $\mathrm{T} 2 \mathrm{a}$ & 106 & 52.4 & & & & \\
\hline $\mathrm{T} 2 \mathrm{~b}$ & 69 & 47.3 & & & & \\
\hline T3 & 84 & 17.1 & & & & \\
\hline \multicolumn{7}{|l|}{ N, AJCC 8th ed. } \\
\hline N0 & 103 & 72.4 & $<0.001^{\mathrm{a})}$ & 1.948 & $1.398-2.713$ & $<0.001^{\text {a) }}$ \\
\hline N1 & 70 & 23.4 & & & & \\
\hline N2 & 18 & 12.5 & & & & \\
\hline \multicolumn{7}{|c|}{ Lymphovascular invasion } \\
\hline Present & 90 & 24.1 & $<0.001^{\mathrm{a})}$ & 1.241 & $0.784-1.964$ & 0.357 \\
\hline Absent & 258 & 62.1 & & & & \\
\hline \multicolumn{7}{|l|}{ Perineural invasion } \\
\hline Present & 95 & 27.1 & $<0.001^{\mathrm{a})}$ & 0.948 & $0.589-1.525$ & 0.824 \\
\hline Absent & 253 & 61.4 & & & & \\
\hline \multicolumn{7}{|l|}{ Margin status } \\
\hline Present & 39 & 17.2 & $<0.001^{\mathrm{a})}$ & 1.293 & $0.670-2.495$ & 0.444 \\
\hline Absent & 309 & 53.9 & & & & \\
\hline
\end{tabular}

(Continued to the next page) 
Table 3. Continued

\begin{tabular}{|c|c|c|c|c|c|c|}
\hline \multirow[b]{2}{*}{ Variable } & \multirow[b]{2}{*}{$\begin{array}{c}\text { No. of } \\
\text { patients }\end{array}$} & \multicolumn{2}{|c|}{ Univariate analysis } & \multicolumn{3}{|c|}{ Multivariate analysis } \\
\hline & & $\begin{array}{c}\text { 5-Year } \\
\text { survival }(\%)\end{array}$ & p-value & $\begin{array}{c}\text { Hazard } \\
\text { ratio }\end{array}$ & $\begin{array}{c}95 \% \\
\text { Confidence } \\
\text { interval }\end{array}$ & p-value \\
\hline \multicolumn{7}{|c|}{ Liver invasion $^{\text {b) }}$} \\
\hline Present & 42 & 16.4 & $<0.001^{\mathrm{a})}$ & & & \\
\hline Absent & 306 & 54.7 & & & & \\
\hline
\end{tabular}

AJCC, American Joint Committee on Cancer. ${ }^{a}$ Significant at the level of $\mathrm{p}<0.05$, ${ }^{\mathrm{b}}$ Not included for multivariate analysis because liver invasion is a component of the $\mathrm{T}$ category.

Significant predictors of poor overall survival included infiltrative growth pattern $(\mathrm{p}<0.001)$, moderate or poor differentiation $(\mathrm{p}<0.001)$, lymphovascular $(\mathrm{p}<0.001)$ and perineural $(\mathrm{p}<0.001)$ invasions, resection margin involvement $(\mathrm{p}<0.001)$, and liver invasion $(\mathrm{p}<0.001)$. However, univariate analysis revealed no significant difference in the overall survival based on age, sex, or tumor histology.

To assess whether $\mathrm{T}$ and $\mathrm{N}$ categories would remain as a predictor of overall survival death after adjusting these factors, multivariate analyses were performed. As Table 3 shows, after adjusting for the adverse pathologic factors, such as tumor size, growth pattern, differentiation, lymphovascular and perineural invasion, and resection margin positivity, only $\mathrm{T}(\mathrm{p}=0.017)$ and $\mathrm{N}(\mathrm{p}<0.001)$ categories remained the most significant predictors of overall survival in patients with gallbladder cancers.

\section{Discussion}

In the 7th edition scheme of gallbladder cancer staging in the AJCC, only tumor depth or invasion to other organs was included in the $\mathrm{T}$ category as other hollow viscous organs [11]. However, several previous studies supported the evidence that tumor location could be a prognostic factor in patients with gallbladder cancer [10,14-16]. Therefore, the new 8 th edition subdivided T2 category of the previous 7 th edition into T2a and T2b. These changes are based on a previous study by Shindoh et al. [10] who analyzed 252 gallbladder cancer cases with T2 disease and found that tumors in the hepatic side had higher vascular and neural invasion and nodal metastasis, and patients with hepatic side tumor had worse survival than those with tumors in the serosal side [10]. However, in the present study, significant survival differences were not observed between patients with T2a and $\mathrm{T} 2 \mathrm{~b}$ tumors, but significant survival differences were obser- ved between T1 and T2 and T2 and T3 comparisons without dividing subcategories. The thickness of the normal gallbladder wall ranges from 0.1 to $0.2 \mathrm{~cm}$ [17]. Therefore, excessive subdivision of gallbladder cancer staging based on the histologic layer may not properly differentiate survival difference based on different $\mathrm{T}$ categories. In contrast, we demonstrated the T category of the 8th edition without dividing for the subcategories could determine the survival time in patients with gallbladder cancers. Therefore, simplified T category without dividing for the subcategories may provide better survival data.

In contrast to the $\mathrm{T}$ category, the 8th edition staging scheme for the $\mathrm{N}$ category clearly determines the survival difference, when we evaluated $\geq 6$ examined lymph nodes as recommended by the 8 th edition staging manual. Our results are concordant with one previous Western study [18]. However, the survival difference between patients with N1 and N2 gallbladder cancers disappeared, when we examined $<6$ lymph nodes or all cases with any number of harvested lymph nodes. These results showed that when the number of examined lymph nodes is $<6$, the $\mathrm{N}$ category can possibly be understaged and more efforts, such as additional lymph node dissections, are required for precise expectation in the survival of surgically resected patients with gallbladder cancers.

In addition, although no significant survival difference was observed, 5-year survival rate of N0 patients with $<6$ examined lymph nodes $(69.8 \%$ ) was slightly lower than those with $\geq 6$ examined lymph nodes $(72.2 \%)$. Close postoperative follow-up may be needed for $\mathrm{N} 0$ patients with $<6$ examined lymph nodes and further investigations with large number of cases are required.

However, in clinical practice, some patients do not show evidence of regional lymph node metastasis on preoperative imaging studies as well as no lymph node enlargement is detected at the operation field. In such cases, the number of harvested lymph nodes can be $<6$ despite extensive lymph node dissection. Thus dissection of six or more lymph nodes 
does not seem to be mandatory for accurate staging if N0 is highly anticipated during operation. In contrast, if regional lymph node metastasis is suspected, it is strongly recommended to resect all dissectable lymph nodes.

In this study, 157 tested patients underwent cholecystectomies without lymph node dissection. The majority of them were incidentally detected with gallbladder cancers and repeated extended resection could not be performed due to various reasons, including early cancer stage, old patient age, major co-morbidity, and patient reluctance. So far, survival information from the $\mathrm{T}$ category has been more focused on patients incidentally detected with gallbladder cancer, because estimated patients' survival was solely dependent on the $\mathrm{T}$ category without knowing the survival data in patients without nodal dissection. The overall survival time in patients without nodal dissection was significantly poorer than those with N0 patients but better than those with N1 patients because of possibility of missed lymph node metastasis. Thorough retrospective review of the preoperative and early postoperative imaging studies is necessary to make more reliable radiological staging. Therefore, as it was pointed out in one previous study [19], close postoperative follow-up is recommended to the patients with gallbladder cancer without nodal dissection, especially during the first year, as like in those with $\mathrm{N} 1 / 2$ cases.

We evaluated the $\mathrm{N}$ category with $>6$ lymph nodes as recommended by the 8th edition of the AJCC staging manual. However, no consensus has been made for the cut-off number of lymph nodes examined. Several previous studies in Japan recommended to evaluate a minimum of six lymph nodes [20-22]. In contrast, one study proposed to examine at least four lymph nodes [18]. Therefore, further studies are required to identify the best cut-off number of lymph nodes evaluated in gallbladder cancers.

This study has several strengths and limitations. The strength is the relatively large number of patients examined, and whether with minimum of six lymph node harvest recommended by the 8 th edition scheme is significant in the survival stratification of the $\mathrm{N}$ category and stage grouping. One of the limitations is results of a retrospective study from a single center with limited cases and statistical power is weak. Therefore, multi-institutional validation studies of the 8th edition $\mathrm{T}$ and $\mathrm{N}$ categories for gallbladder cancer are required.

In summary, the current $\mathrm{T}$ category for gallbladder cancer in the 8th edition of the AJCC staging system did not completely stratify patients' survival. Modification of the present $\mathrm{T}$ category by eliminating the subcategories can determine a better way to stratify the prognosis of patients with gallbladder cancer. In contrast, the $\mathrm{N}$ category clearly determines the patients' survival with $\geq 6$ examined lymph nodes. The survival of patients with gallbladder cancers without nodal dissection is between $\mathrm{N} 0$ and $\mathrm{N} 1$ categories, and close postoperative follow-up is recommended in patients with gallbladder cancer without nodal dissection.

\section{Conflicts of Interest}

Conflict of interest relevant to this article was not reported.

\section{References}

1. Vijayakumar A, Vijayakumar A, Patil V, Mallikarjuna MN, Shivaswamy BS. Early diagnosis of gallbladder carcinoma: an algorithm approach. ISRN Radiol. 2013;2013:239424.

2. Jung KW, Won YJ, Oh CM, Kong HJ, Lee DH, Lee KH, et al. Cancer statistics in Korea: incidence, mortality, survival, and prevalence in 2014. Cancer Res Treat. 2017;49:292-305.

3. Ahn Y, Park CS, Hwang S, Jang HJ, Choi KM, Lee SG. Incidental gallbladder cancer after routine cholecystectomy: when should we suspect it preoperatively and what are predictors of patient survival? Ann Surg Treat Res. 2016;90:131-8.

4. Muszynska C, Lundgren L, Lindell G, Andersson R, Nilsson $\mathrm{J}$, Sandstrom P, et al. Predictors of incidental gallbladder cancer in patients undergoing cholecystectomy for benign gallbladder disease: Results from a population-based gallstone surgery registry. Surgery. 2017;162:256-63.

5. Elmasry M, Lindop D, Dunne DF, Malik H, Poston GJ, Fenwick SW. The risk of malignancy in ultrasound detected gall- bladder polyps: a systematic review. Int J Surg. 2016;33 Pt A:28-35.

6. Ethun CG, Postlewait LM, Le N, Pawlik TM, Buettner S, Poultsides $\mathrm{G}$, et al. A novel pathology-based preoperative risk score to predict locoregional residual and distant disease and survival for incidental gallbladder cancer: a 10-institution study from the U.S. Extrahepatic Biliary Malignancy Consortium. Ann Surg Oncol. 2017;24:1343-50.

7. Hawkins WG, DeMatteo RP, Jarnagin WR, Ben-Porat L, Blumgart LH, Fong Y. Jaundice predicts advanced disease and early mortality in patients with gallbladder cancer. Ann Surg Oncol. 2004;11:310-5.

8. American Cancer Society. Cancer facts and figures 2017. Atlanta, GA: American Cancer Society; 2017.

9. Amin MB, Edge S, Greene F, Byrd DR, Brookland RK, Washingotn MK, et al. AJCC cancer staging manual. 8th ed. New York: Springer; 2017. 
10. Shindoh J, de Aretxabala X, Aloia TA, Roa JC, Roa I, Zimmitti $\mathrm{G}$, et al. Tumor location is a strong predictor of tumor progression and survival in T2 gallbladder cancer: an international multicenter study. Ann Surg. 2015;261:733-9.

11. Edge SB, Byrd DR, Compton CC, Fritz AG, Greene FL, Trotti A. AJCC cancer staging manual. 7th ed. New York: Springer; 2009.

12. Amini N, Spolverato G, Kim Y, Gupta R, Margonis GA, Ejaz $\mathrm{A}$, et al. Lymph node status after resection for gallbladder adenocarcinoma: prognostic implications of different nodal staging/scoring systems. J Surg Oncol. 2015;111:299-305.

13. Lee SE, Kim KS, Kim WB, Kim IG, Nah YW, Ryu DH, et al. Practical guidelines for the surgical treatment of gallbladder cancer. J Korean Med Sci. 2014;29:1333-40.

14. Wakai T, Shirai Y, Sakata J, Nagahashi M, Ajioka Y, Hatakeyama K. Mode of hepatic spread from gallbladder carcinoma: an immunohistochemical analysis of 42 hepatectomized specimens. Am J Surg Pathol. 2010;34:65-74.

15. Shirai Y, Tsukada K, Ohtani T, Watanabe H, Hatakeyama K. Hepatic metastases from carcinoma of the gallbladder. Cancer. 1995;75:2063-8.

16. Endo I, Shimada H, Takimoto A, Fujii Y, Miura Y, Sugita M, et al. Microscopic liver metastasis: prognostic factor for patients with pT2 gallbladder carcinoma. World J Surg. 2004;
28:692-6.

17. Lindberg MR. Diagnostic pathology: normal histology. 2nd ed. Philadelphia, PA: Elsevier; 2017.

18. Kim Y, Amini N, Wilson A, Margonis GA, Ethun CG, Poultsides $\mathrm{G}$, et al. Impact of chemotherapy and external-beam radiation therapy on outcomes among patients with resected gallbladder cancer: a multi-institutional analysis. Ann Surg Oncol. 2016;23:2998-3008.

19. Kasumova GG, Tabatabaie O, Najarian RM, Callery MP, Ng SC, Bullock AJ, et al. Surgical management of gallbladder cancer: simple versus extended cholecystectomy and the role of adjuvant therapy. Ann Surg. 2017;266:625-31.

20. Shimada H, Endo I, Fujii Y, Kamiya N, Masunari H, Kunihiro $\mathrm{O}$, et al. Appraisal of surgical resection of gallbladder cancer with special reference to lymph node dissection. Langenbecks Arch Surg. 2000;385:509-14.

21. Sakata J, Shirai Y, Wakai T, Ajioka Y, Hatakeyama K. Number of positive lymph nodes independently determines the prognosis after resection in patients with gallbladder carcinoma. Ann Surg Oncol. 2010;17:1831-40.

22. Endo I, Shimada H, Tanabe M, Fujii Y, Takeda K, Morioka D, et al. Prognostic significance of the number of positive lymph nodes in gallbladder cancer. J Gastrointest Surg. 2006;10:9991007. 